\section{Examining factors associated with heavy episodic drinking among college undergraduates}

\author{
Kristen Scholly, Alan R. Katz, Lisa Kehl \\ University of Hawaii at Manoa, Honolulu, \\ HI, USA
}

\section{Abstract}

Heavy episodic drinking among college students is a serious health concern. The purpose of this study was to identify factors associated with heavy episodic drinking behaviors amongst a predominately Asian undergraduate college student population in the United States. A survey measuring alcohol use behaviors was completed by a random sample of 18 24 year old undergraduates during April, 2011. A multivariate logistic regression analysis was conducted to determine factors associated with students' heavy episodic drinking behavior. Independent factors associated with heavy episodic drinking included living on campus, ethnicity, perceived drinking behavior among peers, and a belief that alcohol is a central part of one's social life. Heavy episodic drinking was also associated with poor academic performance. Campus-wide educational strategies to reduce heavy episodic drinking among college undergraduates should incorporate accurate information regarding alcohol use norms to correct students' perceived over estimation of their peers alcohol consumption rates and the under estimation of students protective alcohol use behaviors. These efforts should focus in on-campus residence halls where a higher occurrence of heavy episodic drinking is often found.

\section{Introduction}

College heavy episodic drinking is a serious and chronic young adult health problem in the United States. ${ }^{1,2}$ According to the National College Health Assessment (NCHA), a national research survey organized by the American College Health Association (ACHA), heavy episodic drinking or binge drinking, is the consumption of five or more alcoholic drinks in one sitting. ${ }^{3}$ Recent NCHA, 2012 research indicates $66 \%$ of college students surveyed drank alcohol in the last 30 days and approximately $34 \%$ indicated that they had consumed five or more drinks in one sitting over the last two weeks. ${ }^{3}$

Heavy episodic drinking related problems such as injuries, driving under the influence, risky sexual behaviors and sexual assault are all too frequent occurrences on college campuses. ${ }^{4}$ In addition, heavy episodic drinking among college students is associated with missing class, falling behind in schoolwork and an overall lower grade point average. ${ }^{2}$ Even students who do not engage in heavy episodic drinking behavior are at higher risk for the secondhand effects of other students' heavy drinking. Some of these secondhand effects can include: exposure to aggressive and violent behavior, disruption of sleep, and student property damage. ${ }^{2}$

Previous research indicates that there is an increased likelihood to drink more heavily when college students live in the residence halls. ${ }^{5}$ A majority of students who live in campus residence halls are first year students. On average this group tends to show increased alcohol consumption as they transition from high school to college. ${ }^{6}$ Decreased adult supervision, overall greater personal freedom, and increased opportunity to use alcohol, are likely contributors to higher rates of heavy episodic drinking in the residence halls. ${ }^{6}$

The purpose of this study was to identify both risk and protective factors associated with heavy episodic drinking behaviors amongst a predominately Asian undergraduate college student population in the United States. In addition, this study aims to determine whether perceptions of alcohol use amongst peers are associated with an individual's heavy episodic drinking behavior.

\section{Materials and Methods}

This study utilizes data from an alcohol use survey distributed to a random sample of 2500 undergraduates at a Carnegie classified Research I institution. The survey was developed and pilot tested for face and content validity and several of the survey items were based on items from the NCHA, a nationally recognized college health survey. ${ }^{3}$ This study was reviewed and approved by the university's institutional review board.

The survey was created and uploaded into Survey Monkey and a web link was e-mailed to the survey participants in April, 2011 and completed surveys were accepted throughout a three week period. As part of the study, students were asked to report on their personal characteristics, frequency and amount of alcohol use, and perceptions of peers' alcohol use behaviors. Similar to the NCHA 2012, the survey item used in this study to measure heavy episodic drinking behavior asked students if they had consumed five or more alcoholic drinks at a sitting during the last two weeks.

The 18-24 year old age range was selected, as previous research indicates that this age
Correspondence: Kristen Scholly, University Health Services, Queen Liliuokalani Center for Student Services, Room 313D, University of Hawaii at Manoa, Honolulu, HI 96822, USA.

Tel.: +1.808.956.4493 - Fax: +1.808.956.6371

E-mail: kristen@hawaii.edu

Key words: adolescents, alcohol use behaviors, college health, heavy episodic drinking, social norms.

Acknowledgements: a special thank you to Courtney Voss, Graduate Assistant, for her help and support with this research project.

Contributions: KS, study design, survey development, data analysis, and writing of the research article; ARK, data analysis and writing and reviewing the research article; LK, study design, survey development, data analysis, and writing of the research article.

Conflict of interests: the authors declare no potential conflict of interests.

Funding: this study was funded in part by a grant from the Anheuser Busch Foundation.

Received for publication: 15 March 2013.

Revision received: 12 April 2013.

Accepted for publication: 12 April 2013.

This work is licensed under a Creative Commons Attribution NonCommercial 3.0 License (CC BYNC 3.0).

(O)Copyright K. Scholly et al., 2014

Licensee PAGEPress, Italy

Health Psychology Research 2014; 2:1457

doi:10.4081/hpr.2014.1457

group has a high incidence of alcohol misuse. ${ }^{7,8}$ In addition, only those respondents who indicated they had consumed alcohol at least once within the last 12 months were included in the study. Descriptive statistics and logistic regression analysis were conducted using SPSS version 20.

\section{Results}

\section{Descriptive statistics}

Table 1 provides descriptive statistics results. The mean age of the study sample was 21 years old, and the majority of students in this study identified as Asian/part Asian (63\%) and female (64\%). This is comparable to the undergraduate ethnic and gender distribution on the campus (48\% Asian/part Asian and 55\% female). The survey response rate was $39 \%$, with a total of 895 out of 2500 students completing the survey. Adopting criteria to include all students ages 18-24 who consumed alcohol 
within the last year, resulted in a final sample size of 451 respondents. Twenty-six percent of students lived in on-campus housing, also representative of the overall percentage of students living on-campus within the target population. Thirty-one percent of students indicated that within the last two weeks they engaged in heavy episodic drinking.

\section{Logistic regression analysis}

Table 2 provides the results of the logistic regression analysis examining the association between the independent variables and students' likelihood of exhibiting heavy episodic drinking behavior.

Males were more likely than females to report binge drinking $(\mathrm{OR}=2.055, \mathrm{P}<0.01)$. Living on campus was also associated with an increased likelihood of heavy episodic drinking behavior $(\mathrm{OR}=2.583, \mathrm{P}<0.01)$. Asian/part Asian students were less likely to engage in heavy episodic drinking behavior when compared to non-Asians $(\mathrm{OR}=0.547, \mathrm{P}<0.05)$.

Perception of peers' drinking behavior was significantly related to the increased likelihood of heavy episodic drinking. Students who believed that the typical student on campus consumed 5 or more drinks the last time he/she partied, were more likely to engage in heavy episodic drinking behavior themselves $(\mathrm{OR}=1.881, \mathrm{P}<0.05)$.

The belief that alcohol is a central part of social life also increased students' likelihood for engaging in heavy episodic drinking behavior. Students who placed a higher level of importance on drinking in their social life had an increased likelihood for heavy episodic drinking $(\mathrm{OR}=5.503, \mathrm{P}<0.001)$.

Finally, in terms of consequences of alcohol use, students who reported having a hangover
$(\mathrm{OR}=3.825, \mathrm{P}<0.001)$ or having performed poorly on a test, important project, or at work due to their drinking demonstrated an increased likelihood for heavy episodic drinking behavior $(\mathrm{OR}=3.036, \mathrm{P}<0.01)$.

\section{Discussion}

An important aspect of this study was its ability to identify several variables independently associated with college students' likelihood of engaging in heavy episodic drinking behavior. Consistent with previous studies, males were more likely to binge drink compared with females. ${ }^{5}$ Living on campus was also associated with an increased likelihood for heavy episodic drinking behavior. Students in coeducational campus housing were more likely to report heavy episodic drinking, compared to those students who reported living offcampus with parents. ${ }^{2,5,9}$ Previous literature has also shown that Asian students engage in lower rates of heavy episodic drinking behavior in college, when compared to other ethnic student groups such as Caucasians. ${ }^{4,10}$ It is interesting to note that despite being the

Table 1. Demographic, descriptive, and alcohol use characteristics for 18-24 year old, undergraduate college students $(n=451)$.

\begin{tabular}{lc}
\hline Independent variables & Mean (SD) \\
Age in years & $21(1.6)$ \\
Male & 0.36 \\
\hline International student & 0.04 \\
College athlete & 0.14 \\
\hline Live on campus & 0.26 \\
High GPA* $\geq 3.0)$ & 0.62 \\
\hline Full time student & 0.95 \\
Asian/part Asian & 0.63 \\
\hline Pace drinks to one or fewer per hour in the last school year & 0.45 \\
Perception that typical student engages in heavy episodic drinking & 0.64 \\
\hline Perception that the typical student paces their alcoholic drinks to one or fewer per hour & 0.14 \\
Perception that alcohol is a central part of your social life & 0.27 \\
\hline Experienced hangover within the last school year & 0.55 \\
Performed poorly at school or work due to alcohol use within the last school year & 0.10 \\
\hline Engaged in heavy episodic drinking one or more times in the last two weeks & 0.31 \\
\hline
\end{tabular}

*Grade point average on a 4.0 scale; ${ }^{\circ}$ dependent variable. SD, standard deviation.

Table 2. Multivariate logistic regression analysis examining the association between independent variables and heavy episodic drinking among 18-24 year old undergraduate college students $(n=451)$.

\begin{tabular}{|c|c|c|c|c|c|c|}
\hline \multirow[t]{2}{*}{ Independent variables } & \multirow[t]{2}{*}{ B } & \multirow[t]{2}{*}{ SE } & \multirow[t]{2}{*}{$\mathbf{P}$} & \multirow{2}{*}{$\begin{array}{c}\text { OR } \\
{[\operatorname{Exp}(B)]}\end{array}$} & \multicolumn{2}{|c|}{$95 \% \mathrm{CI}$ for $\mathrm{OR}$} \\
\hline & & & & & Lower & Upper \\
\hline Male & 0.720 & 0.277 & $0.009 * *$ & 2.055 & 1.193 & 3.540 \\
\hline Asian & -0.604 & 0.273 & $0.027^{*}$ & 0.547 & 0.320 & 0.934 \\
\hline International student & 0.135 & 0.702 & 0.848 & 1.144 & 0.289 & 4.528 \\
\hline College athlete & -0.025 & 0.366 & 0.945 & 0.975 & 0.476 & 1.996 \\
\hline Full time student & -0.324 & 0.588 & 0.582 & 0.723 & 0.228 & 2.292 \\
\hline High $\mathrm{GPA}^{\circ}(\geq 3.0)$ & 0.103 & 0.280 & 0.714 & 1.108 & 0.640 & 1.918 \\
\hline Live on campus & 0.949 & 0.303 & $0.002^{* *}$ & 2.583 & 1.427 & 4.673 \\
\hline Perception that typical student consumed $5+$ drinks last time he/she partied & 0.632 & 0.292 & $0.030^{*}$ & 1.881 & 1.062 & 3.332 \\
\hline Perception that typical student paces drinks to one or fewer per hour & -0.578 & 0.390 & 0.138 & 0.561 & .261 & 1.205 \\
\hline Performed poorly at school or work due to alcohol use & 1.110 & 0.436 & $0.011^{*}$ & 3.036 & 1.292 & 7.133 \\
\hline Experienced hangover & 1.341 & 0.298 & $0.000 * * *$ & 3.825 & 2.134 & 6.855 \\
\hline Perception that alcohol is central part of social life & 1.705 & 0.295 & $0.000 * * *$ & 5.503 & 3.087 & 9.810 \\
\hline Constant & -2.550 & 0.707 & $0.000^{* * *}$ & 0.078 & & \\
\hline
\end{tabular}

B, beta coefficient; SE, standard error; OR, odds ratio; $\mathrm{Cl}$, confidence interval. ${ }^{*} \mathrm{P}<0.05,{ }^{* *} \mathrm{P}<0.01,{ }^{* *} \mathrm{P}<0.001 ;{ }^{\circ}$ Grade point average on a 4.0 scale. 
largest ethnic group on campus, Asian/part Asian students were still less likely than nonAsians to engage in heavy episodic drinking behavior. The current study finding may be linked to the fact that parental influence has been identified as a protective factor against heavy drinking among Asian American adolescents and the fact that Asian/part Asian students in this study were more likely to live at home with parents than to live in the campus residence halls. 11

The current study also demonstrated a significant association between students' perceived campus alcohol norms and their personal alcohol use behavior. Students who believed that their peers consumed alcohol more heavily than the actual campus norm were also more likely to engage in heavy episodic drinking behavior.

Social norms theory has demonstrated that students often misperceive the frequency with which their peers engage in unhealthy behaviors and that these misperceptions have an impact on individual behavior.12,13 For example, when an overestimation of campus alcohol use exists, it can serve as a false standard to justify heavy episodic drinking. ${ }^{12}$ It may also encourage students engaging in low risk behaviors to increase their risk-taking as a means of conforming to the misperceived peer norms. ${ }^{14}$

Misperceptions regarding alcohol use behavior among college students can result from a number of sources including cultural perceptions of what is considered normal on a college campus, assuming that peers' behavior is typical, and an overall acceptance regarding the frequency of peers' risk-taking behaviors. ${ }^{15}$ In addition, peer alcohol use norms become particularly important in peer-intensive contexts, such as college residence halls, where students lack frequent contact with parents and other outside reference groups. 12

The belief that alcohol is a central part of social life also increased students' likelihood for engaging in heavy episodic drinking behavior. This may reflect a misperception of drinking norms on campus. Previous research has shown that those students who adopted heavy episodic drinking patterns in college did so because they believed that everyone else was drinking, or because they believed that drinking allowed them to fit in with others. 5 Those students who try to conform to inaccurately perceived heavy episodic drinking behaviors on campus may also inflate the importance of alcohol use among their peers. ${ }^{12}$ It may also be that students with a higher incidence of heavy episodic drinking associate themselves more closely to peers with similar perceptions of the importance of drinking and college social life.

Finally, the study demonstrated an association between heavy episodic drinking and negative academic outcomes. ${ }^{2}$ This research find- ing is a serious concern because students who consistently experience hangovers or demonstrate poor academic/work performance may be jeopardizing their health and future careers.

\section{Limitations}

The study's findings should be interpreted in light of some key limitations. First, the data used in this study was cross-sectional thus limiting the researchers' ability to draw causal inferences. Another limitation is the generalizability of the study's findings. It is possible that some students may refrain from reporting their own heavy drinking behavior, even within the context of an anonymous survey. However, the reported prevalence of heavy episodic drinking and the overall survey response rate in this study is comparable to other college behavioral health surveys such as the National College Health Assessment. ${ }^{3}$

The study population was representative of the target population of undergraduate students at the university involved; however the participants were predominately Asian/part Asian, which may limit the study's generalizability to reflect the behaviors of all students currently enrolled in higher education institutions. Nevertheless, findings from this study are consistent with previously published studies among other US college student populations. Additional research is needed to examine factors that contribute to heavy episodic drinking behavior among college undergraduates from a more in-depth, and longitudinal, perspective. Future studies could examine the degree of overestimation of peers' alcohol use behaviors as these peer perceptions relate to students' own ethnic group norms.

\section{Conclusions}

Previous college health research has demonstrated that peer norms are the strongest predictors of high risk drinking on college campuses. ${ }^{12}$ As a result, there is also a need to develop effective strategies which reduce heavy episodic drinking on college campuses. Given how strongly students' alcohol use behaviors are associated with perceptions of their peers' alcohol use behaviors, campus-wide educational efforts should include social norms interventions to help students adopt more realistic, less exaggerated views of their peers' drinking behaviors. ${ }^{12}$ Social norms interventions that creatively provide credible data about students' actual alcohol use behaviors can help correct misperceptions and reduce unhealthy behavior by norming moderate alcohol use on campus. Social norms marketing campaigns are effective in heightening awareness and reducing health risk behaviors such as binge drinking and tobacco use among the college population. ${ }^{16}$ Since heavy episodic drinking is more common in the residence halls, social norms initiatives should be directed toward students living in on-campus housing. 5,12 The importance of implementing effective interventions that reduce heavy episodic drinking among college undergraduates is underscored by the potential repercussions for students' academic success and more importantly for their lifelong health and well-being.

\section{References}

1. Dawson DA, Grant BF, Stinson FS, Chou PS. Another look at heavy episodic drinking and alcohol use disorders among college and noncollege youth. J Stud Alcohol 2004;65:477-88.

2. Wechsler H, Nelson TF. What we have learned from the Harvard School of Public Health college alcohol study: focusing attention on college student alcohol consumption and the environmental conditions that promote it. J Stud Alcohol Drugs 2008;69:481-90.

3. American College Health Association. American College Health AssociationNational College Health Assessment II: Reference Group Data Report Spring 2012. Linthicum, MD: American College Health Association; 2012.

4. Wechsler H, Lee JE, Kuo M, Lee H. College binge drinking in the 1990s: a continuing problem. Results of the Harvard School of Public Health 1999 college alcohol study. J Am Coll Health 2000;48:199-210.

5. Lewis MA, Neighbors C. Social norms approaches using descriptive drinking education: a review of the research on personalized normative feedback. J Am Coll Health 2008;54:213-8.

6. Fromme K, Corbin WR, Kruse MI. Behavioral risks during the transition from high school to college. Dev Psychol 2008;44:1497-504.

7. Jessor R, Costa RM, Krueger PM, Turbin MS. A developmental study of heavy episodic drinking among college students: the role of psychosocial and behavioral protective and risk factors. J Stud Alcohol 2006;67:86-94.

8. Weitzman ER, Nelson TF, Wechsler H Taking up binge drinking in college: the influences of person, social group, and environment. J Adolesc Health 2003;32:2635.

9. Gfroerer JC, Greenblatt JC, Wright DA. Substance use in the US college-age population: Differences according to educational status and living arrangement. Am J 
Public Health 1997;87:62-5.

10. Paschall MJ, Bersamin M, Flewelling RL. Racial/ethnic differences in the association between college attendance and heavy alcohol use: a national study. J Stud Alcohol 2005;66:266-74.

11. Iwamoto DK, Corbin W, Fromme K. Trajectory classes of heavy episodic drinking among Asian American college students. Addiction 2010;10:1912-2

12. Perkins HW. Social norms and the prevention of alcohol misuse in collegiate con- texts. J Stud Alcohol Suppl 2002:164-72.

13. Scholly K, Katz AR, Cole D, Heck RH. Factors associated with adverse sexual outcomes among college students. Am J Health Stud 2010;25:176-85.

14. Scholly K, Katz AR, Gascoigne J, Holk PS. Using social norms theory to explain perceptions and sexual health behaviors of undergraduate college students: an exploratory study. J Am Coll Health 2005;53:159-66.

15. Martens MP, Page JC, Mowry ES, et al.
Difference between actual and perceived student norms: an examination of alcohol use, drug use, and sexual behavior. J Am Coll Health 2006;54:295-300.

16. Berkowitz AD. An overview of the social norms approach. In: Lederman LC, Stewart LP, eds. Changing the culture of college drinking: a socially situated health communication campaign. Cresskill, NJ: Hampton Press; 2005. pp 193-214. 